\title{
CARACTERIZAÇÃO QUÍMICA E MINERALÓGICA DE DIFERENTES ROCHAS DE ORIGEM SEDIMENTAR E MAGMÁTICA
}

\section{ARTIGO DE REVISÃO}

KLEIN, Zander Henrique de Lima ${ }^{1}$

KLEIN, Zander Henrique de Lima. Caracterização química e mineralógica de diferentes rochas de origem sedimentar e magmática. Revista Científica Multidisciplinar Núcleo do Conhecimento. Ano 04, Ed. 10, Vol. 11, pp. 90-103. Outubro de 2019.

ISSN: 2448-0959,

Link de

acesso: https://www.nucleodoconhecimento.com.br/engenharia-agricola/origemsedimentar

\section{RESUMO}

O presente artigo tem por foco caracterizar tipos de solos de diferentes regiões do país, avaliando, sobretudo, a sua composição química e mineralógica bem como o seu material de origem. Pretende-se que essas informações possam servir de base para a elaboração de trabalhos que tem como objeto os respectivos solos. A classificação do solo deve ser determinada pela interpretação das características morfológicas e das propriedades físicas, químicas e mineralógicas, observadas a campo e posteriormente analisadas em um laboratório. O solo, quando classificado, é como uma coleção de corpos naturais, visto que possui partes sólidas, líquidas e gasosas, constituídas, contudo, por materiais minerais e orgânicos, ocupando, assim, grande parte do manto superficial dos continentes do Planeta. Os solos, a partir da superfície, são compostos por seções, geralmente, paralelas e distribuídas em camadas (horizontes) que se diferenciam do material de origem devido a adições,

1 Especialista em MBA em Agronegócios e Gestão de Cidades, Engenheiro Agrônomo. 
perdas, translocações e transformações de energia e matéria que atuam ao decorrer do tempo.

Palavras-chave: solo, classificação, químicas, mineralógicas, rochas.

\section{INTRODUÇÃO}

Mudanças cíclicas acontecem, de forma permanente, na Terra (CARNEIRO; GONÇALVES; LOPES, 2009; GONÇALVES; CARNEIRO, 2007). Assim, em um planeta dinâmico, os materiais (tanto da superfície quanto do interior) passam por transformações diversas, sejam elas lentas ou rápidas. Dessa forma, nem mesmo as rochas podem ser consideradas eternas, visto que são afetadas por diversos graus de reciclagem assim como todos os minerais que as constituem e os objetos encontrados na Terra. Nesse sentido, as escalas de tempo das mudanças são bastante variáveis, logo, flexíveis. Assim sendo, o Ciclo das Rochas deve ser encarado como uma teia complexa de transformações da matéria, variando, portanto, desde as mais rápidas até as mais lentas. Essas, em conjunto, no contexto da Tectônica de Placas, acabam determinando as modificações no reino material.

A relevância social deste estudo se concentra na necessidade de se abordar os processos e produtos do ciclo dessas rochas para refletir sobre os ambientes naturais em que ocorrem (CARNEIRO; GONÇALVES; LOPES, 2009; GONÇALVES; CARNEIRO, 2007). Dessa forma, tais transformações acabam participando dos demais ciclos naturais, e, assim, interferem na vida humana, sendo essa a justificativa para a proposição do estudo. Percebe-se que a rocha, quando passa por processos intempéricos, forma camadas de materiais desagregados. Nelas se formam os solos. Nota-se, então, que o material solto dá vida ao desenvolvimento de plantas e pequenos animais que, por sua vez, contribuem para com a decomposição do húmus. Nesse sentido, cabe discorrer sobre as rochas sedimentares e ígneas. A primeira é conhecida como sedimentação. Trata-se de um processo de acumulação de sedimentos em depressões. 
São chamados de bacias sedimentares. Nelas, a depender das condições bem como da profundidade as quais os sedimentos são submetidos, o peso dos sedimentos acumulados assim como a movimentação de fluidos provoca a compactação e a cimentação dos materiais. $O$ processo de transformação de um sedimento em rocha sedimentar é denominado de diagênese (CARNEIRO; GONÇALVES; LOPES, 2009; GONÇALVES; CARNEIRO, 2007). Nesse sentido, as rochas sedimentares são formadas a partir da deposição e da diagênese dos sedimentos provenientes de outras rochas ou de materiais de origem biogênica, ou, ainda, por intermédio da precipitação química de minerais. Sabe-se, também, que rochas sedimentares como o calcário e os diatomitos são formadas a partir de processos químicos e bioquímicos. Além dessas rochas sedimentares existem as ígneas (ou magmáticas) e as metamórficas.

De acordo com a literatura, a distinção entre elas deve ser feita de acordo com os processos geradores (CARNEIRO; GONÇALVES; LOPES, 2009; GONÇALVES; CARNEIRO, 2007). Contudo, existem variações nas condições de formação de rochas que possuem uma mesma origem genética, resultando, assim, em diversos tipos de rocha para cada grupo. As principais características que distinguem os três grupos são materializadas em três categorias: sedimentares, magmáticas e metamórficas. Sabe-se que quando as placas litosféricas se movimentam durante o Tempo Geológico, as rochas sedimentares, metamórficas e ígneas podem ser levadas a ambientes muito diferentes daqueles sob os quais se formaram. Dessa forma, qualquer rocha submetida à ação de altas precisões e temperaturas, além da percolação de fluidos, passar por transformações nos minerais que as constituem bem como modificam a sua estrutura, tornando-se, assim, orientadas.

Tais propriedades definem uma rocha de caráter metamórfico. Já as rochas sedimentares, ou seja, aquelas enterradas em profundidades suficientes bem como submetidas ao calor interno da Terra e às pressões dirigidas, terão, como consequência, a reorientação dos minerais. Esse processo é denominado de metamorfismo (CARNEIRO; GONÇALVES; LOPES, 2009; GONÇALVES; CARNEIRO, 2007). Assim sendo, as rochas metamórficas são formadas por 
transformações na mineralogia, na química e na estrutura de rochas já existentes, devido, sobretudo, a mudanças nos parâmetros físicos (na pressão e na temperatura) e químicos, diferentes, dessa forma, das condições diagenéticas. Nesse sentido, as rochas resultantes do processo de metamorfismo dependem do tipo de rocha e, também, da sua composição mineralógica.

As principais transformações são a recristalização dos minerais e/ou a formação de novos minerais e deformações na estrutura das rochas (como as dobras, a foliação, a lineação e semelhantes) (CARNEIRO; GONÇALVES; LOPES, 2009; GONÇALVES; CARNEIRO, 2007). É comum que durante a deposição, a diagênese e o metamorfismo progressivo de um sedimento argiloso, essas rochas passem por uma série de etapas. Assim, as rochas envolvidas nessas transformações, permaneçam no estado sólido, e, dessa forma, podem formar rochas sedimentares, como o argilito ou o folhelho. Podem, ainda, dar origem às rochas metamórficas, como, por exemplo, a ardósia, filito, xisto e gnaisse. Nesse sentido, se as condições de metamorfismo forem muito intensas, as rochas podem se fundir, parcial ou totalmente, e, assim, gerar magmas.

Esses, ao solidificarem-se, darão origem a novas rochas ígneas (CARNEIRO; GONÇALVES; LOPES, 2009; GONÇALVES; CARNEIRO, 2007). Somente rochas que atingem alta temperatura podem ser capazes de realizar uma fusão total ou parcial do material, ou seja, precisa ser equivalente à dos gnaisses. Dessa forma, o magma formado, caso seja resfriado lentamente, dará origem a uma rocha plutônica. Em caso contrário, caso seja extravasado na superfície da Terra, formará uma rocha vulcânica. Assim sendo, as rochas ígneas originam-se a partir do resfriamento do magma, ou seja, quanto mais leno o processo de cristalização do magma, maior será o tamanho dos cristais a serem formados. Nessa perspectiva, cabe ressaltar que existem três tipos de rochas ígneas: elas podem ser plutônicas ou intrusivas; subvulcânicas ou intrusivas rasas, ou ainda, vulcânicas ou extrusivas.

Destarte, o magma é capaz de migrar dos locais em que se originou para regiões da crosta terrestre em que a pressão é menor, alojando-se, dessa forma, como intruso magmático (CARNEIRO; GONÇALVES; LOPES, 2009; GONÇALVES; CARNEIRO, 
2007). Uma intrusão é capaz de variar em termos de tamanho e forma. Assim, quando atinge grandes proporções, constitui uma câmara magmática. Caso atinja tais condições, o resfriamento do magma favorece o processo de cristalização dos minerais, dando, nesse sentido, origem a rochas ígneas plutônicas, sobretudo aos granitos. As rochas ígneas vulcânicas (também conhecidas como efusivas), formamse quando a migração do magma alcança a superfície da Terra, por meio, principalmente, de processos associados ao tipo de vulcanismo em vigor. Nos vulcões, o magma atinge a superfície da crosta e se resfria rápido ao entrar em contato com a temperatura ambiente, tendo a consolidação das rochas.

A literatura aponta que os basaltos são as rochas vulcânicas mais comuns. Percebese que devido à solidificação quase que instantânea, não há tempo para que os cristais se desenvolvam, e, dessa forma, são muito pequenos bem como invisíveis a olho nu (CARNEIRO; GONÇALVES; LOPES, 2009; GONÇALVES; CARNEIRO, 2007). Em situações nas quais o magma se cristaliza no interior da crosta, próximo, portanto, à superfície, contudo com um resfriamento um pouco mais lento do que as rochas vulcânicas, podem ser formados cristais de tamanho pequeno. Esses, por sua vez, são visíveis a olho nu. Rochas desse tipo são comumente nomeadas de subvulcânicas. Como exemplo pode ser citado o diabásio. Termos como "extrusivo", "vulcânico", "subvulcânico", "hipoabissal", "intrusivo" e "plutônico" devem ser acionados para descrever, geologicamente, os corpos ígneos.

Pode-se concluir esta introdução afirmando que quando são identificadas as diferentes classes dos solos assim como os seus respectivos materiais de origem, é possível observar, com clareza e precisão, diversos fenômenos (CARNEIRO; GONÇALVES; LOPES, 2009; GONÇALVES; CARNEIRO, 2007). Detecta-se, também, a importância de identificar a composição química e mineralógica desses materiais. Esta, por sua vez, influenciará, expressivamente bem como de forma positiva, na fertilidade do solo assim como no seu comportamento mediante intervenções de caráter agrícola. Este comportamento poderá ser alterado em detrimento do uso desses materiais, visto que estão intrínsecos na composição química e mineralógica das rochas que dão origem aos solos. Para tanto, quando se 
propõe discutir sobre o solo e as rochas, deve-se levar em consideração as características regionais da população e os fatores externos.

\section{REVISÃO DE LITERATURA}

\subsection{FORMAÇÃO DAS ROCHAS}

As rochas são formadas a partir de agregados naturais, ou seja, por meio da combinação de um ou mais minerais (CARNEIRO; GONÇALVES; LOPES, 2009; GONÇALVES; CARNEIRO, 2007; SOARES; VAZ, 2012; VALCÁCIO, 2016). Assim, grãos ou cristais bem unidos resultam em rochas duras ou brandas de acordo com o processo de formação. Essa agregação de materiais obedece a leis físicas, químicas ou físico-químicas. O aspecto geral de uma rocha é denominado de estrutura. Este, por sua vez, pode ser maciço, pode possuir cavidades, pode ser orientado, etc. A sua textura pode ser visualizada a partir do tamanho e do relacionamento entre os cristais e os grãos que constituem essa rocha. Em estudos que se ocupam em estudar as rochas, deve-se determinar e refletir sobre os materiais que as constituem. Os minerais presentes e abundantes em uma dada rocha são chamados de essenciais.

Eles atuam como um fator decisivo para definir o nome de uma rocha (CARNEIRO; GONÇALVES; LOPES, 2009; GONÇALVES; CARNEIRO, 2007; SOARES; VAZ, 2012; VALCÁCIO, 2016). De maneira usual, encontra-se dois ou três minerais essenciais em uma rocha. Todavia, um mesmo tipo de rocha pode apresentar variações em suas quantidades. Os minerais essenciais mais comuns que se manifestam nas rochas são o feldspato, o quartzo, o anfibólio-piroxênio, a olivina, a muscovita, a biotita e a nefelina. Os demais minerais são chamados de acessórios. Considerando tal contexto, percebe-se que quando a rocha possui agregação mineralógica de espécie única deve ser compreendida como uma rocha monominerálica. Como exemplo podem ser citados o calcário, o quartzito e o mármore. Contudo, quando as espécies são diferentes, a rocha é denominada de pluriminerálica (como o gnaisse, o gabro e o granito). 
Para concluir este tópico é válido frisar que em relação às proporções aproximadas dos minerais presentes em uma rocha, esta pode ser classificada como leucocrática (quando é rica em minerais claros, como o feldspato e o quartzo), como melanocrática (quando predominam os minerais escuros, como a biotita) ou como mesocrática (são rochas intermediárias, pois há cerca de 30 a $30 \%$ de minerais escuros em sua composição). Sabe-se que o estudo das características macroscópicas, microscópicas, mineralógicas e químicas das rochas permite que essas sejam classificadas segundo esses aspectos (CARNEIRO; GONÇALVES; LOPES, 2009; GONÇALVES; CARNEIRO, 2007; SOARES; VAZ, 2012; VALCÁCIO, 2016). Concluise, então, que as rochas estão distribuídas pela crosta continental (em terras emersas, ou seja, nos continentes) e pela crosta oceânica (no fundo do mar). Assim, 95\% do volume da crosta continental é formado por rochas magmáticas e metamórficas e 5\% é composto por rochas sedimentares.

\subsection{COMPOSIÇÃO QUÍMICA E MINERALÓGICA DAS ROCHAS}

Neste momento inicial será apresentado o arenito caiuá. Segundo Fonseca e Czuy (2005), rochas oriundas do arenito tendem a apresentar uma textura que pode variar de arenosa a média. Assim sendo, conta com um elevado teor de areia bem como com uma baixa porcentagem de argila. Esses aparecem em setores mais elevados da região. De forma geral, são solos extremamente friáveis, e, dessa forma, como consequência, possuem uma elevada suscetibilidade à fenômenos como a erosão. Percebe-se, de acordo com o estudo de Fonseca e Czuy (2005), que os teores de areia tendem a ser de 85 a 90\%. Dessa forma, possuem níveis demasiadamente críticos de elementos como o fósforo, o potássio, o cálcio e o magnésio. Não é raro, também, que possuam baixos níveis de matéria orgânica. Usualmente tais níveis compreendem, apenas, $1 \%$. Assim, frequentemente, pode haver uma deficiência de macro e micronutrientes nas culturas.

Prosseguindo, há os folhelhos. Esses são rochas sedimentares detríticas que apresentam fissilidade, e, assim, são ricas em elementos de fração fina, como os siltes e as argilas (LUCENA; LIRA; AMORIM, 2013; GRUNITZKI; SANTOS, 2012; SANS; DEMATTÊ; CARVALHO, 1977). As rochas sedimentares são resultantes da 
consolidação de sedimentos provenientes da desagregação e do transporte de rochas preexistentes, da precipitação química e da ação biogênica. Dessa forma, a transformação dos sedimentos em rochas ocorre após a sua deposição. Uma série de processos químicos pode ocorrer, como a dissolução, a precipitação, a oxidação, a redução e a recristalização. Pode ocorrer, ainda, processos físicos, conhecidos como diagenéticos, sobretudo em razão de baixas pressões e temperaturas. Os mais frequentes são a cimentação, a compactação e a autigênese.

Por conseguinte, tem-se os arenitos. Estudos apontam que esses possuem como mineralogia essencial quartzo (cerca de 65\%), feldspato potássico (microclínio e ortoclásio) ou plagioclásio sódico (SCHIAVO et al, 2010; MENDES; TRUCKENBRODT, 2009). A fração de argila consiste, geralmente, em sericita, illita, caulinita e clorita. É formado, essencialmente, por rochas clásticas, ou seja, por aquelas cujas partículas apresentam um tamanho de areia bastante fino bem como há a presença de uma areia demasiadamente grossa, e, assim, conta com menos de $25 \%$ de feldspatos e menos de $20 \%$ de minerais de argila em sua composição. Suas características de textura dos arenitos costumam depender, principalmente, do tamanho das partículas clásticas, do grau de arredondamento da partícula, da disposição das partículas, da natureza e da quantidade de cimento. Sua origem é sedimentar.

Existem diversas propriedades que podem ser consideradas para a análise de formação das rochas. Aqui foram apresentadas algumas a título de curiosidade. Dessa forma, para concluir este tópico, é possível apresentar uma última propriedade. Conforme Moreira (1998), o solo areno-argiloso tem uma característica coluvionar. Em detrimento de tal condição, é fisicamente composto, principalmente, por argila e areia. A sua coloração, contudo, possui tons amarelados bem como conta com possíveis resquícios de pedregulhos angulares e subangulares de elementos como o quartzo e as lateritas, de textura granular. Dessa forma, apresenta-se ca partir de um aspecto homogêneo, composto, portanto, por quartzo, caulinita, biotita gnaisse e óxidos de ferro, provenientes, no entanto, de rochas sedimentares. 


\section{METODOLOGIA}

A metodologia deste trabalho tomará forma a partir de uma revisão bibliográfica acerca da classificação de solos, rochas, minerais e materiais de origem de 5 (cinco) regiões específicas: uma no estado de Rondônia, uma no estado da Bahia e três no estado do Paraná. Objetivando obter o máximo de informações a respeito da composição química e mineralógica das rochas que deram origem a estes solos, este estudo é destinado a auxiliar trabalhos posteriores que terão como base ou instrumento de pesquisa os solos destas regiões para que possam, assim, utilizar-se deste trabalho como uma base de informações primárias para a implantação, execução e conclusão dos respectivos trabalhos.

A definição das áreas que serão estudadas neste trabalho foi selecionada com base em pré-projetos do Mestrado Profissional em Agroecologia - PROFAGROEC (MPAUEM), que serão desenvolvidos por alunos das turmas 5 e 6 do Mestrado. Além da revisão bibliográfica, serão realizadas aulas práticas em laboratório que serão ofertadas pela disciplina de Química do solo, ministradas pelo professor Dr. Antônio Carlos Saraiva da Costa, do Mestrado Profissional em Agroecologia - UEM para a identificação de solos, rochas e minerais. A partir disso, os mesmos serão caracterizados quanto aos seus atributos físicos, químicos e mineralógicos. É esta a contribuição acadêmica deste estudo.

\section{RESULTADOS E DISCUSSÃO}

A seguir serão categorizadas as rochas quanto a sua composição química e mineralógica. Tais informações poderão ser consultadas por curiosos, pesquisadores, especialistas e demais interessados na tabela.

Tabela 1: Composição Química e Mineralógica das Rochas

\begin{tabular}{|l|l|l|l|}
\hline SOLO & MATERIA & COMPOSIÇ & COMPOSIÇÃO \\
& L DE & ÃO & MINERALÓGICA E FÓRMULA \\
& ORIGEM & QUÍMICA E & \\
\hline
\end{tabular}




\begin{tabular}{|c|c|c|c|}
\hline & & $\begin{array}{l}\text { PORCENTA } \\
\text { GEM }\end{array}$ & \\
\hline $\begin{array}{l}\text { PVAd-ARENITO } \\
\text { CAIUÁ }\end{array}$ & $\begin{array}{l}\text { SEDIMEN } \\
\text { TAR }\end{array}$ & $\begin{array}{l}\mathrm{SiO}-\mathrm{-} 96,1 \% \\
\mathrm{Al} 2 \mathrm{O} 3-1.1 \% \\
\mathrm{~K} 2 \mathrm{O}-1,4 \% \\
\mathrm{FeO}-2,3 \% \\
\mathrm{CaO}-9,9 \% \\
\mathrm{MgO}-2,4 \% \\
\mathrm{Na} 2 \mathrm{O}-1,0 \% \\
\mathrm{CO} 2-2,7 \% \\
\mathrm{H} 2 \mathrm{O}-9,1 \%\end{array}$ & 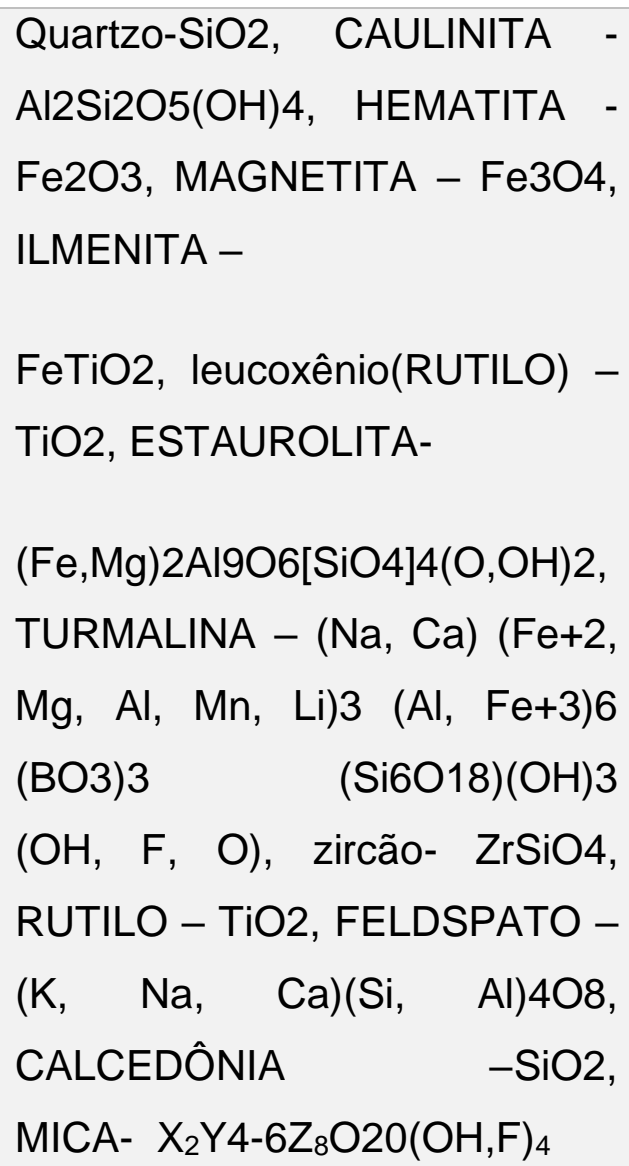 \\
\hline $\begin{array}{l}\text { LVd-ARENITO } \\
\text { CAIUÁ }\end{array}$ & $\begin{array}{l}\text { SEDIMEN } \\
\text { TAR }\end{array}$ & $\begin{array}{l}\text { SiO2- } 96,1 \% \\
\text { Al2O3- } 1.1 \% \\
\text { K2O- } 1,4 \% \\
\text { FeO- } 2,3 \% \\
\mathrm{CaO}-9,9 \% \\
\mathrm{MgO}-2,4 \% \\
\mathrm{Na} 2 \mathrm{O}-1,0 \% \\
\mathrm{CO} 2-2,7 \%\end{array}$ & 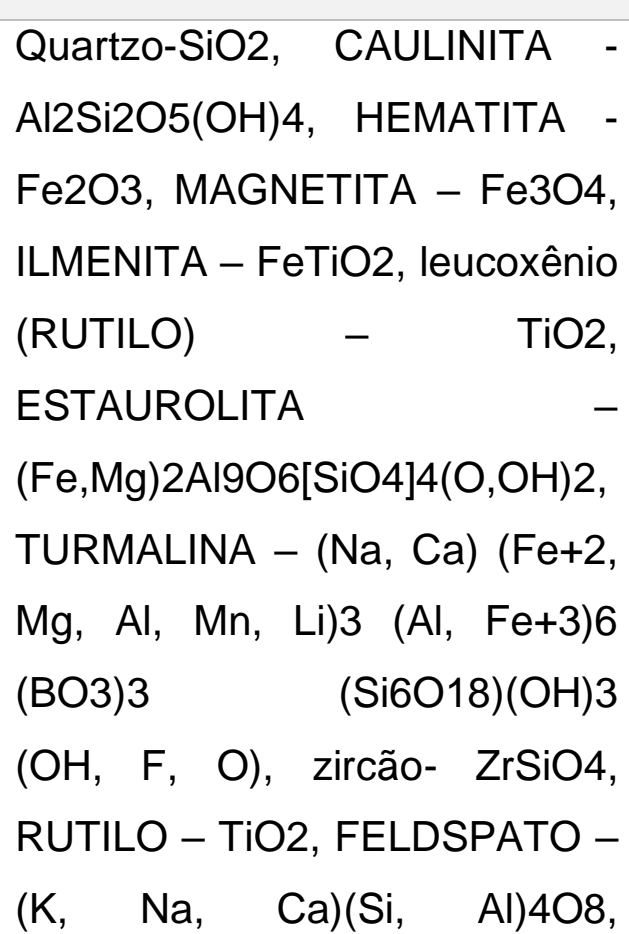 \\
\hline
\end{tabular}




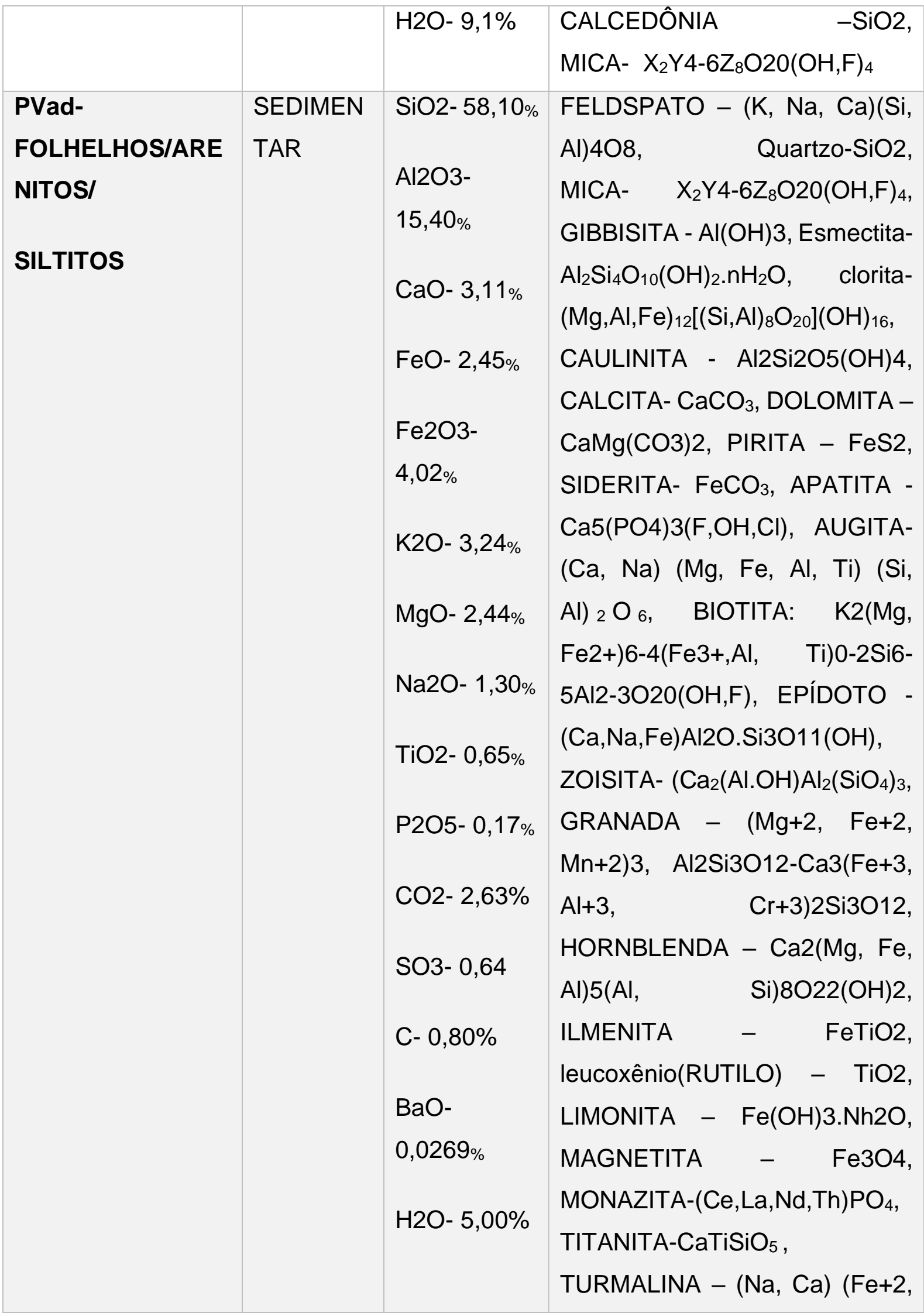




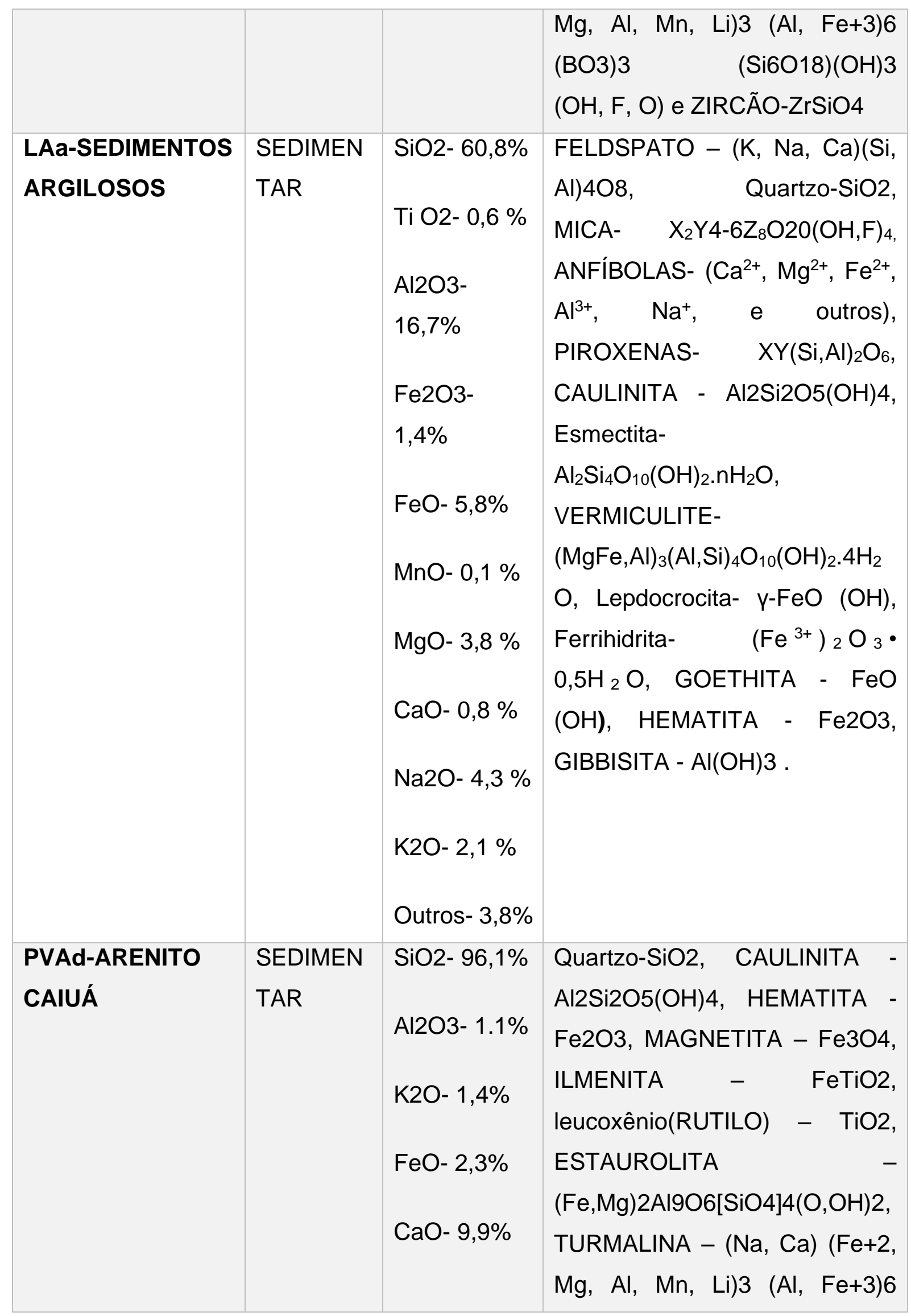




\begin{tabular}{|c|c|c|c|}
\hline & & $\begin{array}{l}\mathrm{MgO}-2,4 \% \\
\mathrm{Na} 2 \mathrm{O}-1,0 \% \\
\mathrm{CO} 2-2,7 \% \\
\mathrm{H} 2 \mathrm{O}-9,1 \%\end{array}$ & 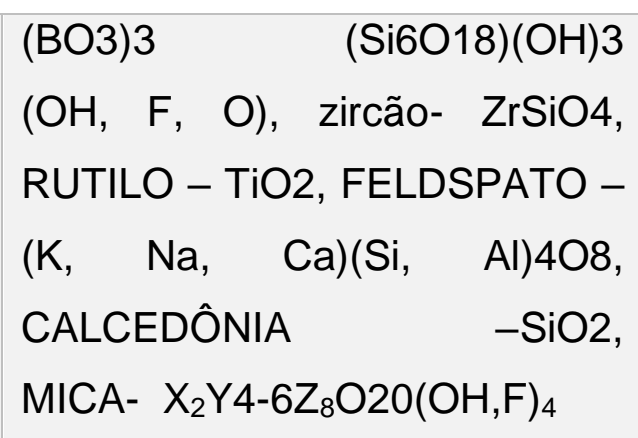 \\
\hline $\begin{array}{l}\text { Rd-FOLHELHOS E } \\
\text { SILTITOS }\end{array}$ & $\begin{array}{l}\text { SEDIMEN } \\
\text { TAR }\end{array}$ & $\begin{array}{l}\mathrm{SiO} 2-58,10 \% \\
\text { Al2O3- } \\
15,40 \% \\
\mathrm{CaO}-3,11 \% \\
\mathrm{FeO}-2,45 \% \\
\mathrm{Fe} 2 \mathrm{O}- \\
4,02 \% \\
\text { K2O- 3,24\% } \\
\text { MgO- } 2,44 \% \\
\text { Na2O- } 1,30 \% \\
\text { TiO2- 0,65\% } \\
\text { P2O5- 0,17\% } \\
\text { CO2- 2,63\% } \\
\text { SO3- } 0,64 \\
\text { C- 0,80\% }\end{array}$ & 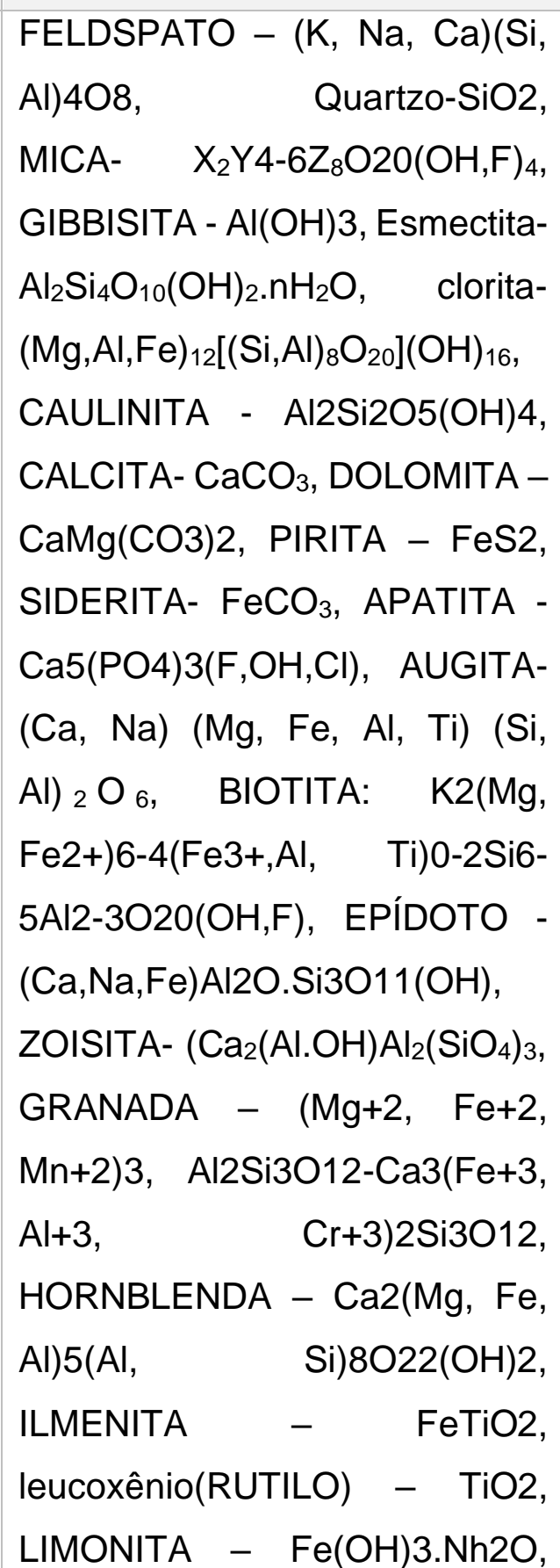 \\
\hline
\end{tabular}




\begin{tabular}{|c|c|c|c|}
\hline & & $\begin{array}{l}\mathrm{BaO}- \\
0,0269 \% \\
\mathrm{H} 2 \mathrm{O}-5,00 \%\end{array}$ & 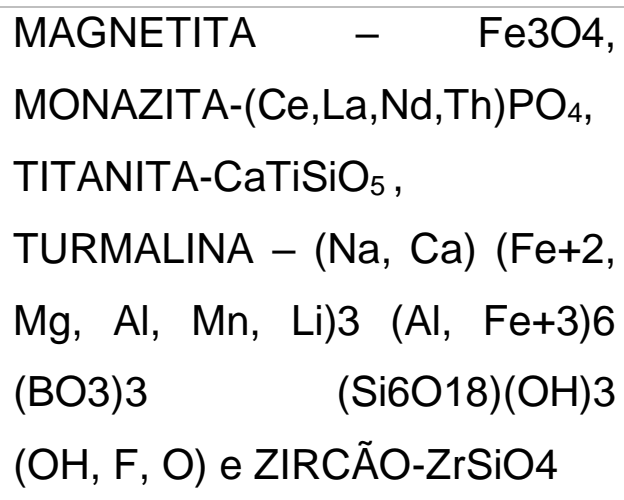 \\
\hline NVef-BASALTO & $\begin{array}{l}\text { MAGMÁTI } \\
\text { CA }\end{array}$ & $\begin{array}{l}\mathrm{SiO} 2- \\
54,58 \% \\
\text { Al2O3- } \\
\text { 14,43\% } \\
\text { TiO2- 1\% } \\
\text { Fe2O3- } \\
10,68 \% \\
\mathrm{MnO}-0,16 \% \\
\mathrm{MgO}-4,51 \% \\
\mathrm{CaO}-7,63 \% \\
\mathrm{Na2O}- \\
1,48 \% \\
\mathrm{P} 2 \mathrm{O} \%- \\
0,23 \% \\
\mathrm{LO}-2,08 \% \\
\end{array}$ & $\begin{array}{l}\text { PIROXENAS- } \quad \mathrm{XY}(\mathrm{Si}, \mathrm{Al})_{2} \mathrm{O}_{6}, \\
\text { Olivina-(Mg,Fe })_{2} \mathrm{SiO}_{4}, \\
\text { Plagioclásio- } \\
\text { (Na,Ca)Al(Si,Al)Si }{ }_{2} \mathrm{O}_{8}, \\
\text { ANFÍBOLAS- }\left(\mathrm{Ca}^{2+}, \mathrm{Mg}^{2+}, \mathrm{Fe}^{2+} \text {, }\right. \\
\mathrm{Al}^{3+}, \mathrm{Na}^{+}, \text {e outros). }\end{array}$ \\
\hline
\end{tabular}




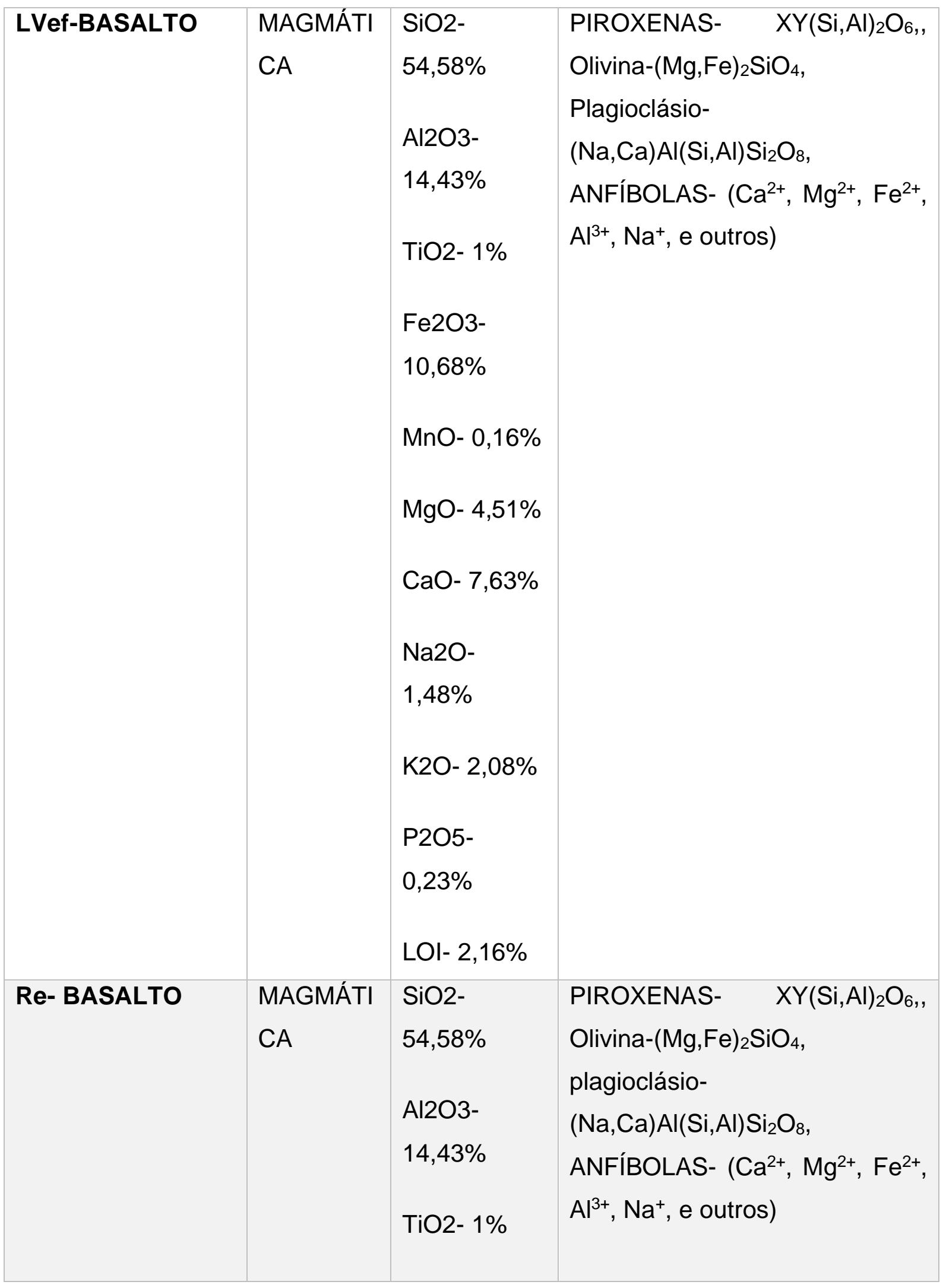




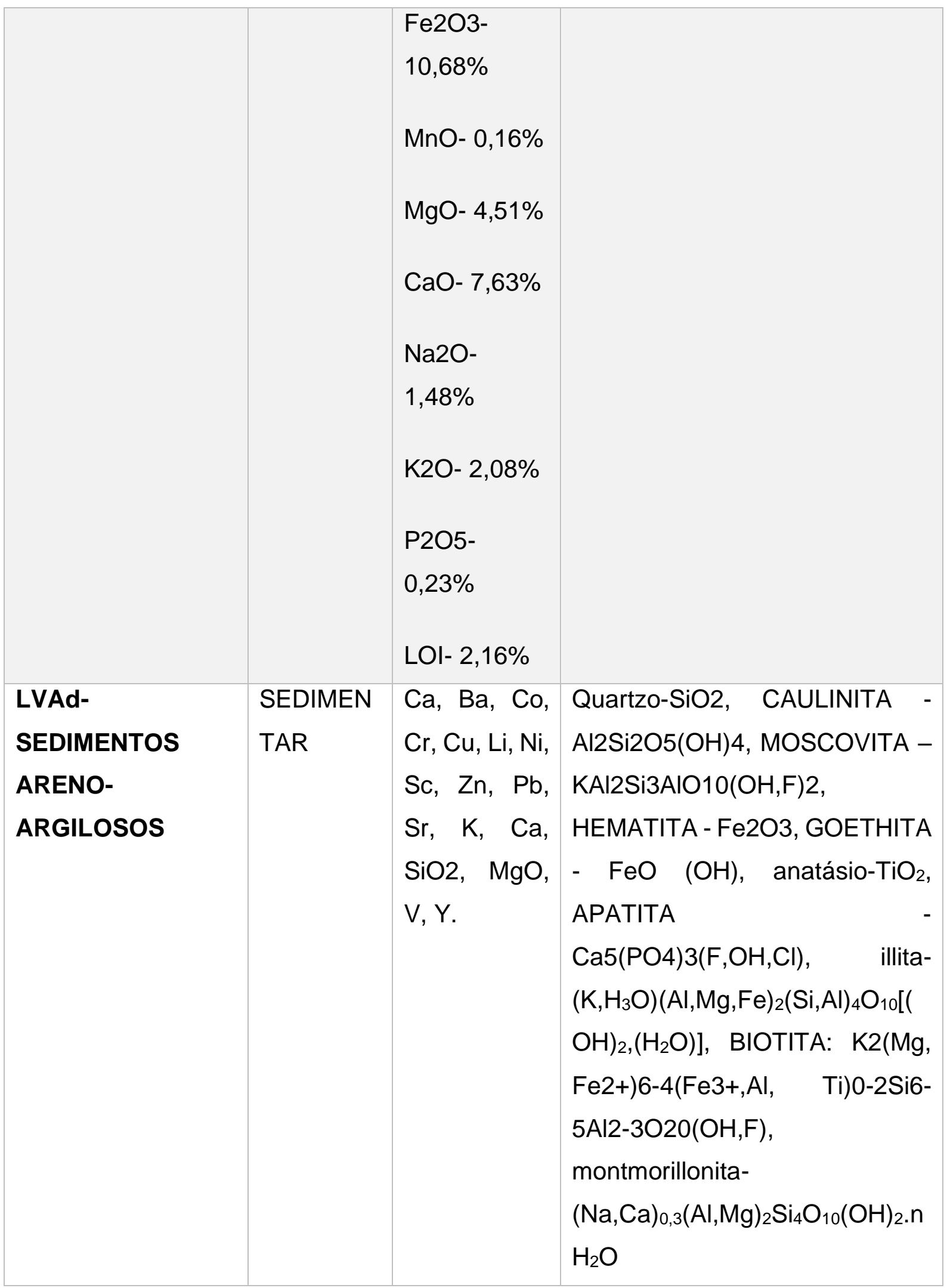




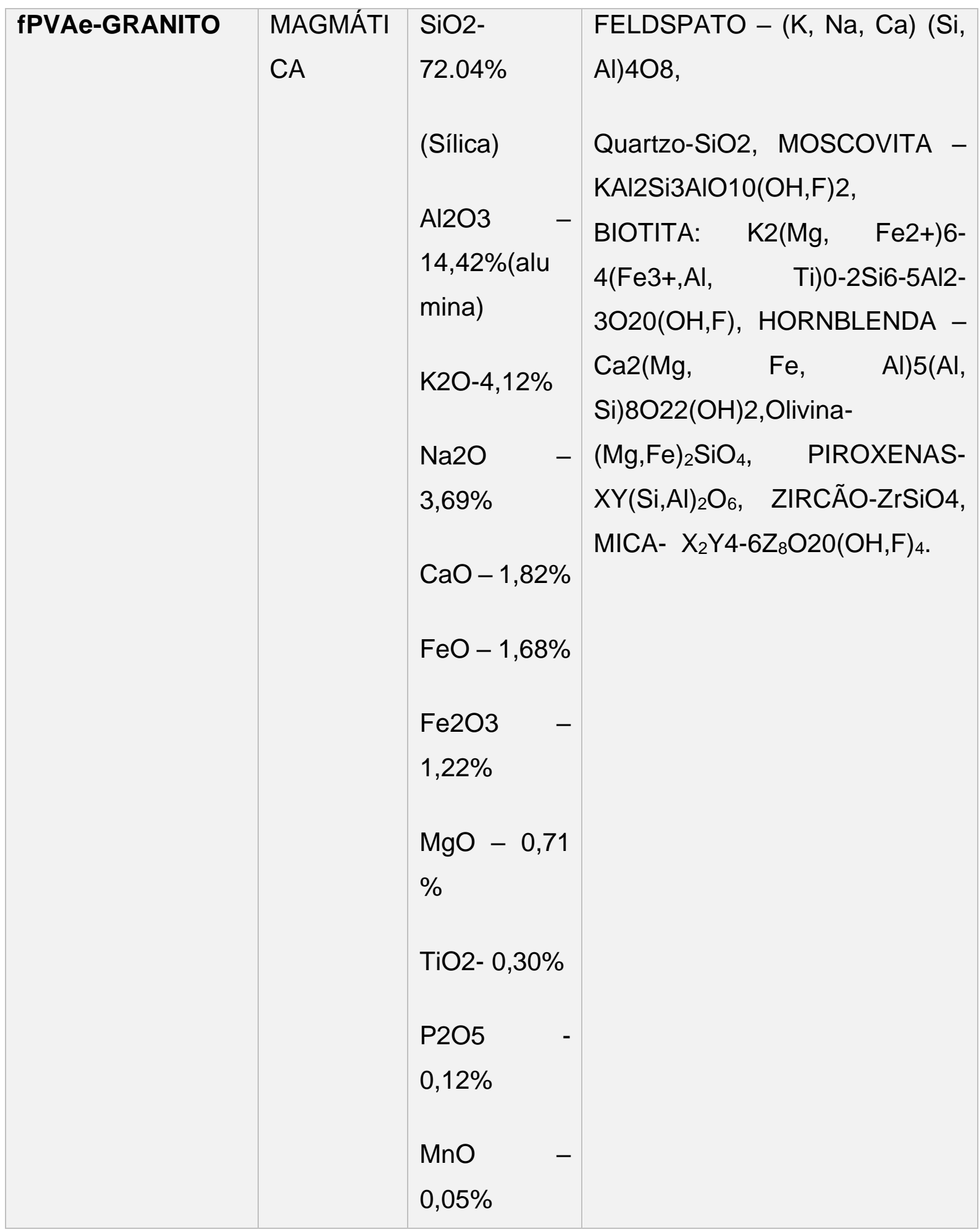

Fonte: elaborado pelo autor (2019)

De acordo com a tabela acima foram levantadas as características químicas e mineralógicas dos solos selecionados pelos alunos do Mestrado Profissional em 
Agroecologia - UEM - das turmas 05 e 06 , sendo 07 solos de origem de rochas sedimentares e 04 solos de origem de rochas magmáticas. Dentre os solos de rochas sedimentares tem-se: 03 solos PVAd - ARGISSOLO VERMELHO- AMARELO distrófico, 01 solo LVd- LATOSSOLO VERMELHO distrófico, 01 solo LAaLATOSSOLO AMARELO ácrico, 01 solo Rd- SOLO LITÓLICO DISTRÓFICO e 01 solo LVAd- LATOSSOLO VERMELHO-AMARELO distrófico. Os solos de rochas magmáticas são: 01 solo NVef - NITOSSOLO VERMELHO Eutroférrico, 01 solo LVefLATOSSOLO VERMELHO eutroférrico, 01 solo Re- NEOSSOLO LITÓLICO Eutrófico e 01 solo PVAe- ARGISSOLO VERMELHO-AMARELO eutrófico. Estes solos serão objetos das dissertações dos alunos do Mestrado que possuem projetos de pesquisa relacionados à sustentabilidade nas respectivas regiões a serem analisadas por meio da agroecologia.

\section{CONCLUSÃO}

Após a caracterização e identificação das rochas que deram origem aos solos mencionados neste trabalho, pode-se observar a composição química que as rochas possuem como base de sua formação os elementos Silício, Alumínio, Ferro, Cálcio e Potássio como principais elementos, sendo estes responsáveis por mais de $90 \%$ da composição das rochas. Já quanto a sua mineralogia deve-se destacar o Quartzo, Feldspato, Mica, Caulinita, Piroxenas, Zircão e Gibbsita como os principais componentes formadores das rochas. Estes elementos e minerais que compõe as rochas tem participação significativa na formação dos solos, sendo, assim, importantes para a determinação dos atributos físicos e químicos dos solos, e, consequentemente, da sua fertilidade. Sendo assim, os projetos a serem desenvolvidos nestes solos deverão levar estas características em consideração para que os trabalhos tenham uma resposta mais efetiva.

\section{REFERÊNCIAS}

CARNEIRO, C. D. R; GONÇALVES, P. W; LOPES, O. R. O Ciclo das Rochas na Natureza. Terra e Didática, v. 5, n. 1, p. 50-62, 2009. 
FONSECA, F. P; CZUY, D. C. Formação Arenito Caiuá: Uso, ocupação do solo e problemas ambientais na região noroeste do Paraná. In: Simpósio Nacional de Geografia Agrária, 2005.

GONÇALVES, P. W; CARNEIRO, C. D. R. Magmas e rochas ígneas: o estudo do calor interno da Terra. Revista USP, n. 72, p. 62-73, 2006.

GRUNITZKI, C; SANTOS, A. A. dos. Caracterização mineralógica e mecânica do folhelho síltico, são e maciço da região central do município de Criciúma. Artigo para a obtenção do título de Engenheira Civil - Universidade do Extremo Sul Catarinense, Criciúma, 2012.

LUCENA, D. V. de; LIRA, H. de. L; AMORIM, L. V. Caracterização de folhelhos: uma análise sobre a capacidade de expansão. Tecnol. Metal. Miner., v. 10, n. 4, p. 287295, 2013.

MENDES, A. C; TRUCKENBRODT, W. Proveniência de arenitos albianos (Grupo Itapecuru), borda leste da bacia de São Luís-Grajaú, Maranhão, usando análise de minerais pesados e química mineral. Ciências Naturais, v. 4, n. 1, p. 57-74, 2009.

SANS, L. M. A; DEMATTÊ, J. L. T; CARVALHO, A. Características físicas, químicas e mineralógicas de uma catena de solos sobre folhelho. An. Esc. Super. Agric. Luiz de Queiroz, v. 34, p. 45-59, 1977.

SILVA, A. S. da.; VAZ, A. J. Geologia aplicada à Geografia. Rio de Janeiro: Fundação CECIERJ, 2012.

SCHIAVO, J. A. et al. Caracterização e classificação de solos desenvolvidos de arenitos da formação Aquidauna - MS. R. Bras. Ci. Solo, v. 34, p. 881-889, 2010.

VALCÁCIO, S. do. N. Pirometamorfismo provocado por intrusões básicas cenozoicas em rochas da bacia potiguar, RN: integração de dados geológicos e petrofísicos. Dissertação de Mestrado em Geodinâmica e Geofísica - Universidade Federal do Rio Grande do Norte, Natal, 2016. 
Enviado: Agosto, 2019.

Aprovado: Outubro, 2019. 